\title{
The regime of Aerosol Optical Depth and Ångström exponent over Central and South Asia
}

\author{
Athina Avgousta Floutsi ${ }^{1, *}$, Marios Bruno Korras Carraca ${ }^{2}$, Christos Matsoukas ${ }^{2}$, Nikos Hatzianastassiou ${ }^{3}$, and George \\ Biskos $^{4}$ \\ ${ }^{1}$ Leibniz Institute for Tropospheric Research, Permoserstraße 15, 04318 Leipzig, Germany \\ ${ }^{2}$ Department of Environment, University of the Aegean, Mytilene 81100, Greece \\ ${ }^{3}$ Laboratory of Meteorology, Department of Physics, University of Ioannina, 45110 Ioannina, Greece \\ ${ }^{4}$ Energy, Environment, and Water Research Center, The Cyprus Institute, Nicosia 2121, Cyprus
}

\begin{abstract}
Central and South Asia are regions of particular interest for studying atmospheric aerosols, being among the largest sources of desert dust aerosols globally. In this study we use the newest collection (C061) of MODIS - Aqua aerosol optical depth (AOD) at $550 \mathrm{~nm}$ and Ångström exponent (a) at 412/470 nm over the 15-year period between 2002 and 2017, providing the longest analyzed dataset for this region. According to our results, during spring and summer, high aerosol load (AOD up to 1.2) consisting of coarse desert dust particles, as indicated by $a$ values as low as 0.15 , is observed over the Taklamakan, Thar and Registan deserts and the region between the Aral and Caspian seas. The dust load is much lower during winter and autumn (lower AOD and higher $a$ values compared to the other seasons). The interannual variation of AOD and $a$ suggests that the dust load exhibits large decreasing trends (AOD slopes down to -0.22, $a$ slopes up to 0.47 decade $^{-1}$ ) over the Thar desert and large increasing trends between the Aral and Caspian seas (AOD and $a$ slopes up to 0.23 decade $^{-1}$ and down to -0.61 decade $^{-1}$, respectively.) The AOD data are evaluated against AERONET surface-based measurements. Generally, MODIS and AERONET data are in good agreement with a correlation coefficient $(\mathrm{R})$ equal to 0.835 .
\end{abstract}

\section{Introduction}

Climate is changing on local, regional and global scales and an effective way to understand these changes is the quantification of the radiative forcing. Atmospheric aerosols affect the climate through their direct, indirect, and semi-direct effects on the radiative energy budget of the Earth-atmosphere system [1]. Aerosols, however, impose the greatest part of uncertainty in predictions of radiative forcing due to our inadequate knowledge of their spatial and temporal distribution, and of their physicochemical properties, and the processes they are involved in [2]. Therefore, additional studies on the properties of specific aerosol types such as dust that predominate over extended arid or semi-arid world regions like deserts is a critical contribution to the field of climate change. In such studies, use of aerosol data coming from in situ measurements, and especially from satellite observations that provide complete spatial coverage, is essential [1]. The objective of this study is to examine the spatial and temporal variation of the aerosol optical depth (AOD) and the Angström exponent over the area of the Central and South Asia for the period 2002 to 2017, thereby providing a climatological type of dataset for the region by means of satellite-based remote sensing MODIS observations.

*e-mail: floutsi@tropos.de
The regions of Central along with South Asia (hereafter CS Asia, $23^{\circ}-52^{\circ} \mathrm{N}, 45^{\circ}-92^{\circ} \mathrm{E}$, cf. Fig. 1), are of great interest for being one of the largest source of desert dust aerosol globally [3]. Nevertheless, it should be noted that apart from desert dust, anthropogenic aerosols are also present over the climatically sensitive regions of CS Asia, which originate from fossil fuel combustion, occurring mainly at oil refineries in the Caspian Sea basin and in power plants located in northeastern Pakistan as well as urban pollution in highly populated areas.

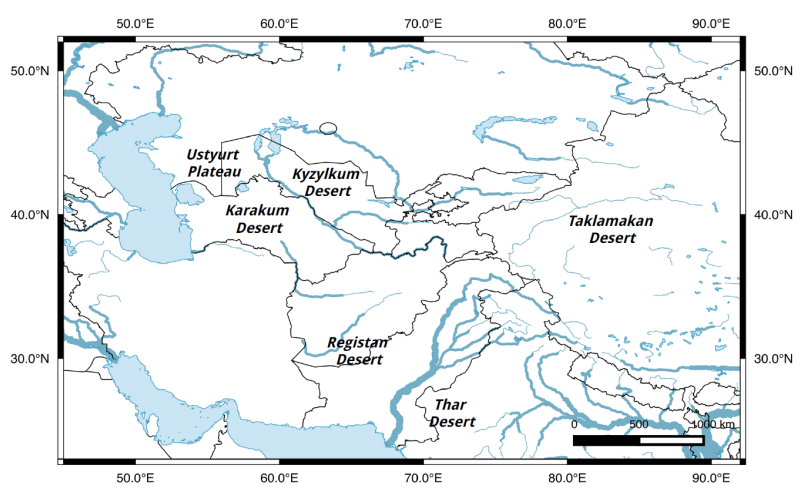

Figure 1. Map of the study region

In the Central Asia region, coarse desert dust particles originate mostly from large deserts (Karakum, Kyzylkum 
and Taklamakan) with additional contributions by the Aral Sea basin. The phenomenal shrinking and desertification of the Aral Sea drives an intense salt and dust transport from the exposed sea-bed to the surrounding regions with important implications in the regional air quality due to the health-hazardous materials contained in the Aral Sea seabed [4]. In the southern parts of our study region desert dust particles originate from arid regions of the Iranian Plateau (such as Registan desert) and the Thar desert, located in the northwestern part of the Indian subcontinent.

This paper is organized as follows: Section 2 provides information on our data sources and data-handling methodology. Section 3 presents our analysis for seasonal and inter-annual behaviour of the MODIS aerosol and the evaluation of the satellite data against ground-based measurements from AERONET. Section 4 discusses the findings and summarizes the most important conclusions of this study.

\section{Data and methodology}

\subsection{MODIS data}

In this study we investigate the spatial and temporal variability of the AOD at $550 \mathrm{~nm}$ and Angström exponent $a$ (which is inversely related to the size of the particles) in the wavelength pair of $412 / 470 \mathrm{~nm}$, over CS Asia. For our analysis we use Level-3 daily MODIS - Aqua Dark Target - Deep Blue combined product for AOD and Deep Blue product for $a$, from the latest collection (061) [5], available in a $1^{\circ} \times 1^{\circ}$ resolution (ca. $100 \mathrm{~km} \times 100 \mathrm{~km}$ ) over the period 04.07.2002-31.12.2017.

\subsection{AERONET data}

We validated the MODIS satellite AOD data against corresponding surface-based measurements from Aerosol Robotic Network (AERONET). AERONET provides total column aerosol properties from sun/sky radiometers [6]. In this study we used Level 2 direct sun observations which are cloud-screened [7] and quality-assured. We selected 10 AERONET stations within our study region, which are presented in Tab. 1.

\subsection{Methodology}

Overall, a total of 5660 daily datasets were analyzed for the two examined aerosol parameters. The AOD and $a$ data were used to produce 15-year (from 2002 to 2017) mean aerosol products, in order to assess their spatial and seasonal variability over the study region. The interannual variability is examined by applying linear regression on the time series of monthly deseasonalized anomalies of AOD and $a$ (for each $1^{\circ} \times 1^{\circ}$ cell) and computing the values of the slope, which is a measure of the sign and magnitude of their 2002-2017 trend.

\section{Results}

\subsection{Spatial Distributions}

Figs. 2 - 5 and 6 - 9 show the spatial distribution of AOD and Ångström exponent, respectively, averaged for each season of the period July 2002 - December 2017. Our results indicate a significant spatial and seasonal variability of the aerosol optical properties over the study region. Generally, during spring and summer, most parts of CS Asia experience a greater aerosol load (higher AOD values) consisting of larger particles (lower $a$ values), compared to autumn and winter. More specifically in Taklamakan desert the maximum AOD (up to 1.00) is observed during spring, associated with a peak of dust activity [8]. During summer the AOD remains relatively high (up to 0.75). The dominance of coarse desert dust particles in this region is also indicated by the very low $a$ values during both spring and summer (down to 0.15). A clear summer peak of the aerosol load is observed in the Northwestern

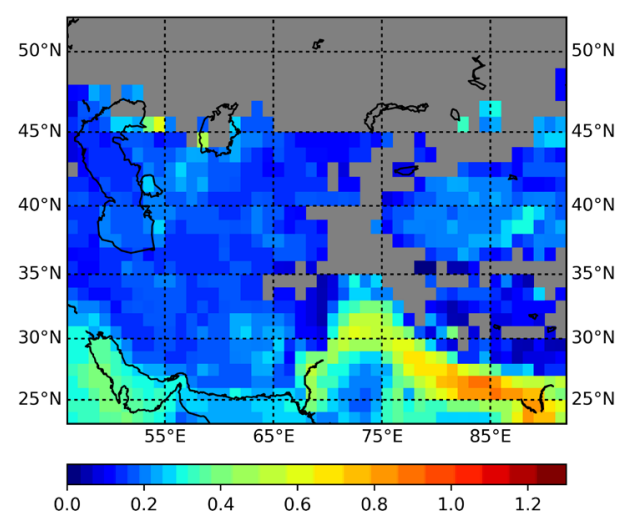

Figure 2. Long-term (2002-2017) average spatial distribution of AOD at $550 \mathrm{~nm}$ for winter.

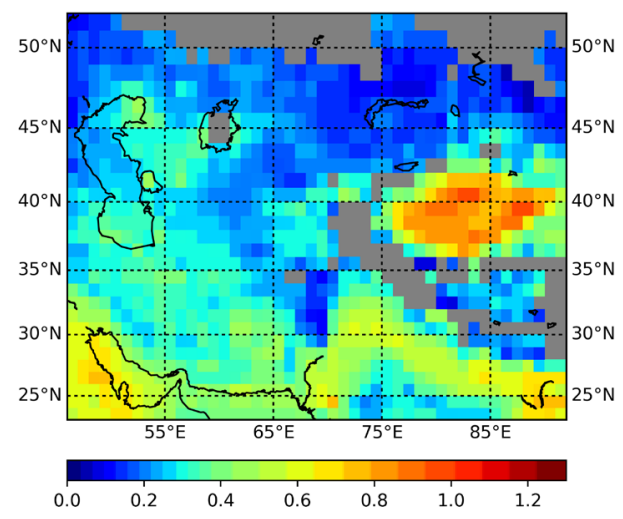

Figure 3. Same as Fig. 2, but for spring. 


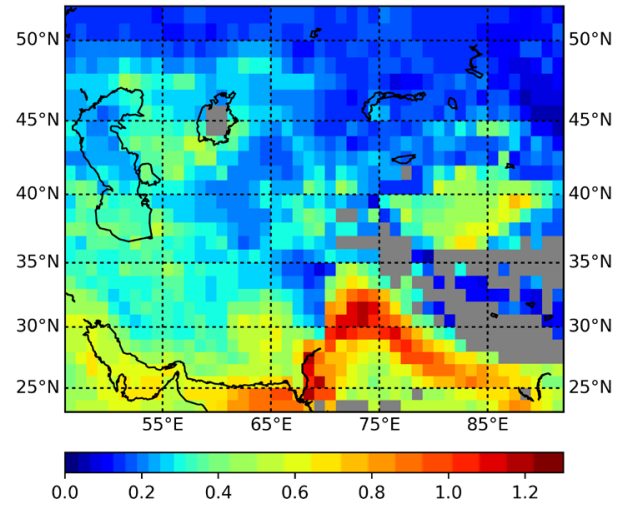

Figure 4. Same as Fig. 2, but for summer.

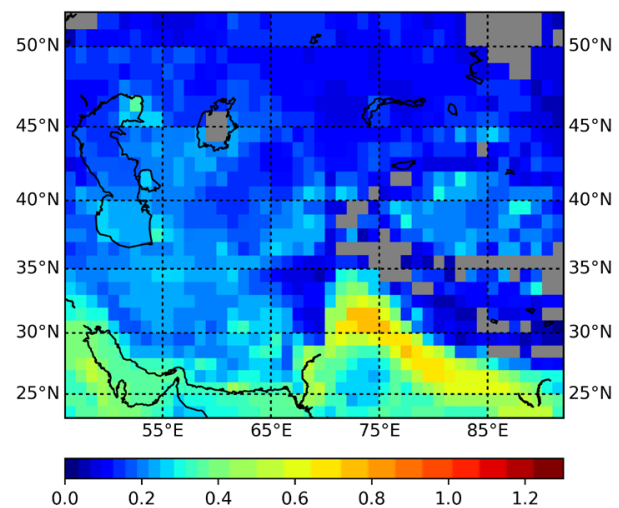

Figure 5. Same as Fig. 2, but for autumn.

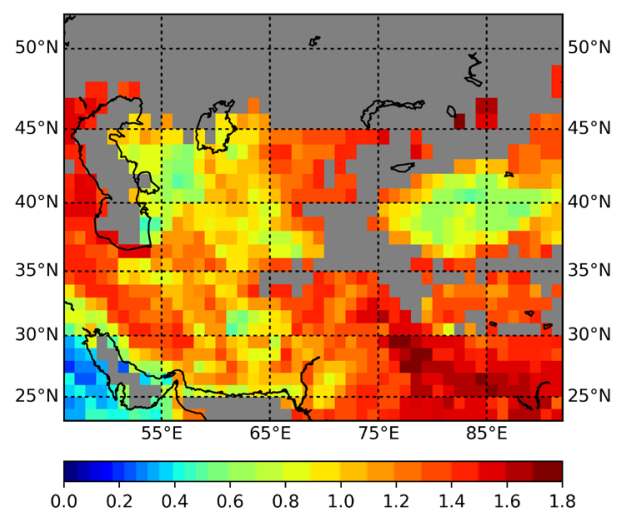

Figure 6. Long-term (2002-2017) average spatial distribution of $a$ at 412/470 $\mathrm{nm}$ for winter.

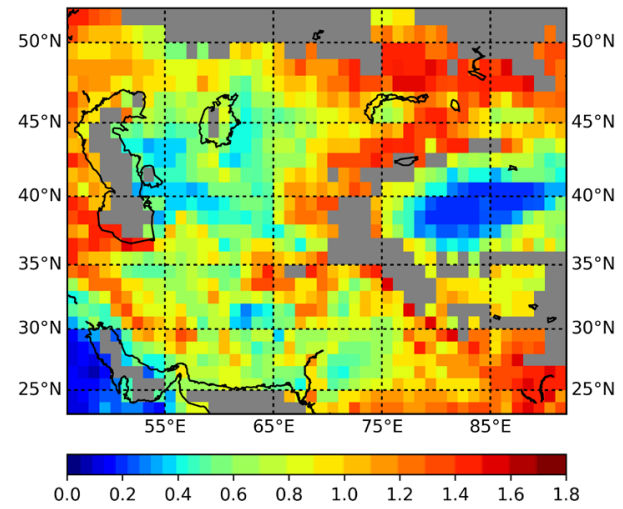

Figure 7. Same as Fig. 6, but for spring.

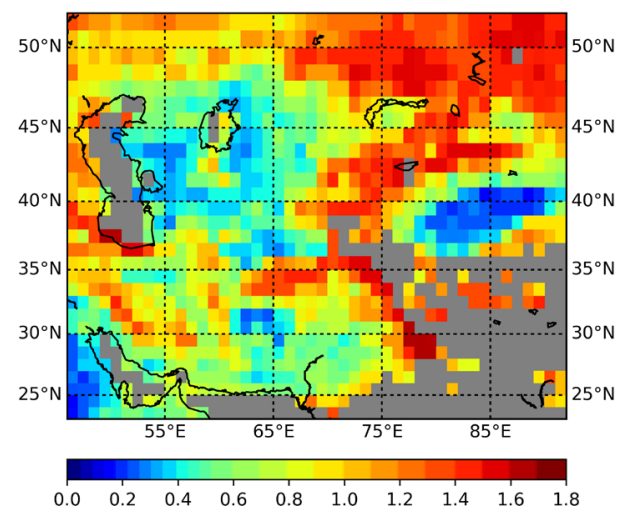

Figure 8. Same as Fig. 6, but for summer.

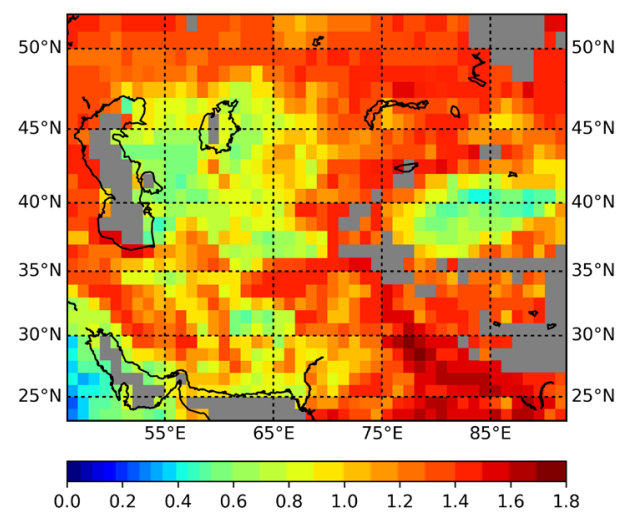

Figure 9. Same as Fig. 6, but for autumn. 
Indian subcontinent with AOD values as high as 1.20. In the Indus river basin, as indicated by the low $a$, the high aerosol load is associated with dust particles originating mainly from the Thar desert [9]. On the other hand, in the Gangetic plain, the high $a$ values indicate the presence of fine mode anthropogenic particles. In the Aral Sea and the northeastern Caspian sea basins and the Ustyurt Plateau the AOD reaches 0.48 in spring and 0.51 in summer, associated with the peak of dust activity. During the same seasons the $a$ values are low (down to 0.31 and 0.27 , respectively). In the Ustyurt Plateau, the high AOD and low $a$ values can be associated with both local dust sources [11] and dust export from the exposed former Aral seabed under strong northerly and north - easterly winds [3]. Relatively high aerosol load consisting mainly by desert dust particles is observed above the Iranian plateau, where during summer the highest AOD (up to 0.64) is observed over the Registan desert, combined with very low $a$ values (down to 0.24). Above most of our study region during autumn and winter the AOD is lower than 0.3. Relatively high aerosol load is observed over the Indo-Gangetic plain (AOD up to 0.90) where it is mainly associated with fine anthropogenic particles as indicated by the large $a$ values.

\subsection{Inter-annual variability}

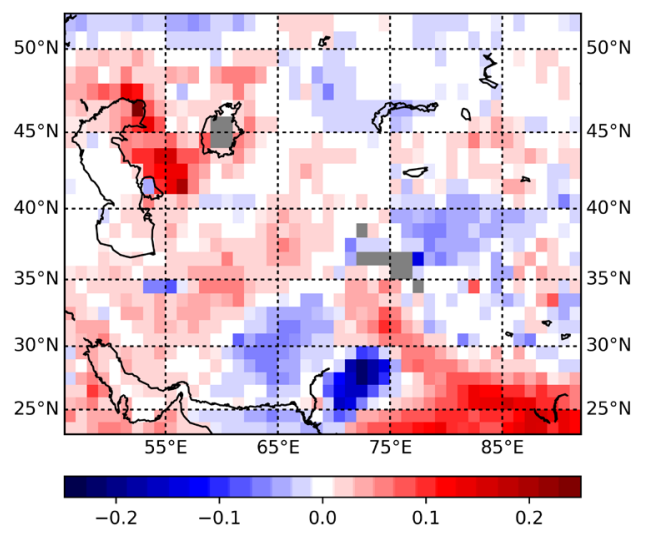

Figure 10. Slope for deseasonalized AOD at $550 \mathrm{~nm}$ (units are decade ${ }^{-1}$ ), over the CS Asia for the period 2002-2017.

In Figs. 10 and 11 the slopes for deseasonalized time series of pixel level AOD and $a$ (both expressed per decade $\left.^{-1}\right)$ are presented. The largest decrease of AOD (down to -0.22 decade $^{-1}$ ) is observed above the Thar desert. In this region the $a$ exhibits a strong increase (up to 0.47 decade $^{-1}$, i.e. decrease of the aerosol size). We can therefore conclude that there is a weakened presence of dust aerosol particles. This trend can be associated with the increase of monsoonal precipitation in the Northwestern Indian subcontinent and the subsequent decrease of dust emission [10]. These tendencies were found to be statistically significant at a 95\% confidence level (not shown here), as determined by the student t-test. Lower decreasing AOD and increasing $a$ trends (though also statistically

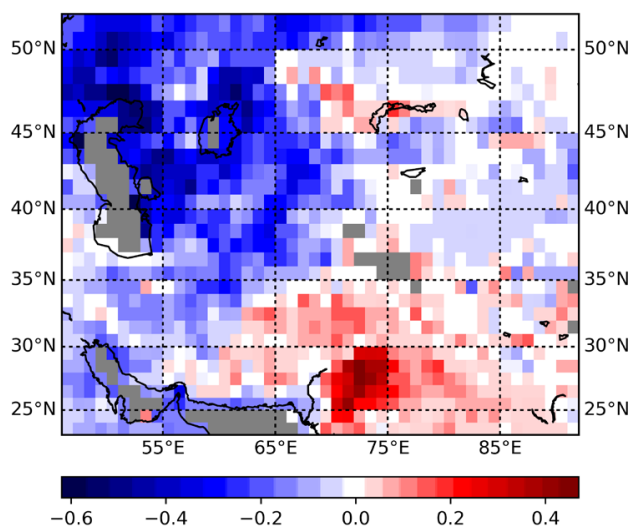

Figure 11. Slope for deseasonalized $a$ at $412 / 470 \mathrm{~nm}$ (units are decade $^{-1}$ ), over the CS Asia for the period 2002-2017.

significant) are also observed over much of Afghanistan, including the Registan desert. On the other hand the highest increase of AOD (up to 0.23 decade $^{-1}$ ) and decrease of $a$ (up to -0.61 decade $^{-1}$ ) tendencies are observed in the northwestern Caspian Sea basin, the Ustyurt Plateau and the Aral Sea basin indicating a strengthened presence of coarse desert dust particles. These trends are also statistically significant and may be associated with the desertification of the Aral Sea basin and the increased dust transport from the exposed sea-bed during the study period. Our results suggest also an increasing of dust load (higher AOD, lower $a$ ) over much of the western parts of the study region. It should be noted that caveats in MODIS data (such as the calibration drift and assumptions regarding the aerosol type) may affect the trends presented, and are not discussed here.

\subsection{Validation with ground-based aerosol data}

The MODIS AOD observations were compared with optical measurements from the global network of AERONET surface stations. For this purpose, using the Ångström Exponent at the wavelength pair of 440-870 nm, we converted the AERONET AOD at $440 \mathrm{~nm}$ to AOD at 550 $\mathrm{nm}$, against which MODIS AOD is evaluated. The stations used for the validation are shown in Tab. 1 along with their geographic coordinates (latitude and longitude), the count, which is the number of common days between MODIS and AERONET per station, the number of the Pearson correlation coefficient and mean bias per station. The mean bias presented is calculated as the difference between the overall average of both datasets $\left(\right.$ data $_{M O D I S}-$ data $\left._{\text {AERONET }}\right)$. Generally, as shown in Fig. 12, the MODIS-Aqua AOD values are in good agreement with the respective data from AERONET. The overall correlation coefficient between the two datasets is 0.835 and the mean bias is 0.015 or $4.4 \%$. The correlation coefficients are larger than 0.7 in 8 stations, and larger than 0.8 in 4. The two stations with bad statistical metrics have only a few data. MODIS AOD is underestimated compared to AERONET at 4 stations and overestimated at 
the remaining 6. The mean bias range is between -0.17 and 0.113. However, in most stations the mean bias is small. The MODIS-AERONET bias tend to be positive in the northern stations and negative in the southern stations, while the scatter of the data is similar in all stations (not shown here).

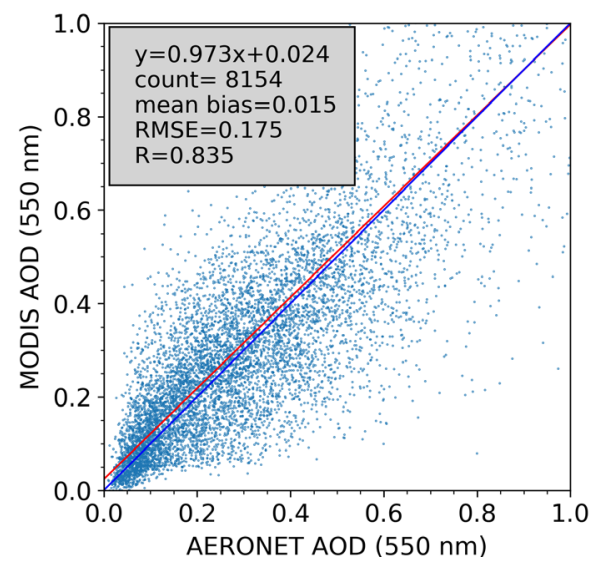

Figure 12. Scatterplot comparison between daily MODIS and AERONET AOD values at $550 \mathrm{~nm}$. The correlation coefficient (R), mean bias and root mean squared error (RMSE) between MODIS and AERONET data are also provided.

\begin{tabular}{|l|r|r|r|r|l|}
\hline Station Name & Lat & Lon & Count & \multicolumn{1}{l|}{$\begin{array}{l}\text { Mean } \\
\text { Bias }\end{array}$} & $R$ \\
\hline \hline Ahmedabad & 23.02 & 72.52 & 8 & -0.170 & 0.303 \\
Dushanbe & 38.55 & 68.86 & 1350 & 0.043 & 0.813 \\
IAOCA-KRSU & 42.46 & 78.53 & 185 & 0.057 & 0.796 \\
IASBS & 36.71 & 48.51 & 827 & 0.094 & 0.799 \\
Issyk-Kul & 42.62 & 76.98 & 1457 & 0.026 & 0.832 \\
Jaipur & 26.91 & 75.81 & 1448 & -0.127 & 0.812 \\
Kandahar & 31.51 & 65.85 & 46 & 0.004 & 0.733 \\
Karachi & 24.95 & 67.14 & 1397 & -0.024 & 0.820 \\
Lahore & 31.48 & 74.26 & 1386 & 0.113 & 0.785 \\
Muztagh Ata & 38.41 & 75.04 & 50 & -0.049 & 0.075 \\
\hline
\end{tabular}

Table 1. Statistical metrics for the comparison of 2002-2017 daily AOD between MODIS and AERONET for the study region. The comparison is performed through the calculation of mean bias (MODIS minus AERONET) and correlation coefficient $\mathrm{R}$.

\section{Conclusions}

The spatial and temporal variability of AOD and Ångström exponent over the Central and South Asia have been inves- tigated using satellite (MODIS-Aqua) data. The obtained results indicate a significant spatio-temporal variability of the aerosol load and size over our study region. High AOD and low $a$ values are observed during the peak of dust activity (spring, summer). The main dust hot-spots in the CS Asia are found to be the Taklamakan, Thar and Registan deserts and the region between the Aral and Caspian seas including the Ustyurt plateau. The dust load has been shown to exhibit large decreasing trends over the northeastern Indian subcontinent and large increasing trends in the northwestern Caspian Sea basin, the Ustyurt Plateau and the Aral Sea basin. The MODIS AOD data were compared against surface measurements from AERONET. The results of the comparison revealed a generally good agreement between the two datasets. Despite the importance and the climatic sensitivity of the study region, the number of AERONET stations is limited and also sparsely distributed. Therefore the deployment of more ground based atmospheric monitoring sites is crucial, for the study of aerosols in this region of large spatiotemporal variability and for the validation of satellite data.

\section{References}

[1] Hatzianastassiou, N. et al., Tellus B 56, 368-381 (2004)

[2] Boucher, O. et al., Climate Change 2013: The Physical Science Basis. Contribution of Working Group I to the Fifth Assessment Report of the Intergovernmental Panel on Climate Change (Cambridge University Press,Cambridge, United Kingdom and New York, NY, USA, 2013) 571-658

[3] Shen, H. et al., Arab. J. Geosci. 9, 625 (2016)

[4] O'Hara, S. L. et al., The Lancet 355, 627-628 (2000)

[5] Hubanks, P. (2017). Collection 6.1 Change Document MODIS Atmosphere Level - 3 Global Products Daily (08_D3), Eight Day (08_E3), Monthly (08_M3). Retrieved from https://modis-atmosphere.gsfc.nasa.gov/ sites/default/files/ModAtmo/L3_C61_Changes.pdf

[6] Holben, B.N. et al., Remote Sens. Environ. 66, 1-16 (1998)

[7] Smirnov, A. et al., Remote Sens. Environ. 73, 337-349 (2000)

[8] Xi, X. et al., J Geophys. Res.-Atmos. 120, 1536-1564 (2015)

[9] Tariq, S. et al., Appl. Ecol. Env. Res. 16, 2615-2637 (2018)

[10] Jin, Q. Wang, C., Scientific reports, 8, 4573 (2018)

[11] Nobakht, M. et al., CADUC proceedings, Web of Conferences (2019) 